\title{
Blashkolinear Psoriasis: A Rare Clinical Form
}

\section{EL Jouari O*, Gallouj S, Lamouaffaq L, Baybay H, and Mernissi FZ \\ Department of Dermatology and Venereology, University Hospital Hassan II Fez,} Morocco

*Corresponding author: Ouiame El Jouari, Department of Dermatology and

\section{Case Report}

Volume 3 Issue 1

Received Date: December 05, 2017

Published Date: January 11, 2018

DOI: $10.23880 /$ cdoaj-16000138

Venereology, University Hospital Hassan II Fez, Morocco, Tel: 00212645768798; E-mail: eljouariouiame@gmail.com

\section{Abstract}

Linear psoriasis is a rare clinical presentation of psoriasis. It is characterized by linear erythematous and scaly lesions along the lines of Blaschko and usually appears in childhood. Its Pathogenesis could be explained by the concept of genetic mosaicism. We report a rare, but a typical and an interesting case of linear psoriasis a 13 year old girl with onset at the age of 2 months.

Keywords: Psoriasis; Blashkow's lines

\section{Introduction}

Linear psoriasis is a rare clinical presentation of psoriasis. It is characterized by linear erythematous and scaly lesions along the lines of Blaschko and usually appears in childhood. Its Pathogenesis is still unknown. A few cases have been reported in the literature.

\section{Case Report}

A 13-year-old girl presenting asymptomatic linear erythematous and scaly lesions, with onset at the age of 2 months, having progressively increased in number and in size. There was no family history of psoriasis. The dermatological examination revealed erythematous plaques covered by whitish scales, along the lines of Blaschko, interesting the limbs and the trunk (Figures 13 ). The Sign of the curette was negative. There were no mucous, nail or scalp lesions. The dermoscopic examination showed a regular and homogeneous diffuse dotted vascularisation (Figure 4). The main differential diagnosis was related to the inflammatory linear verrucous epidermal nevus and lichen striatus. A skin biopsy was performed to confirm the diagnosis of psoriasis linear and removed an interface lichenoid reaction (Figure 5). The patient was treated with a topical Clobetasol 0, 05\%, without evident response.UVB phototherapy 3 times a week for 10 weeks had been associated. In 4 weeks there was a significant decrease of the plaques.

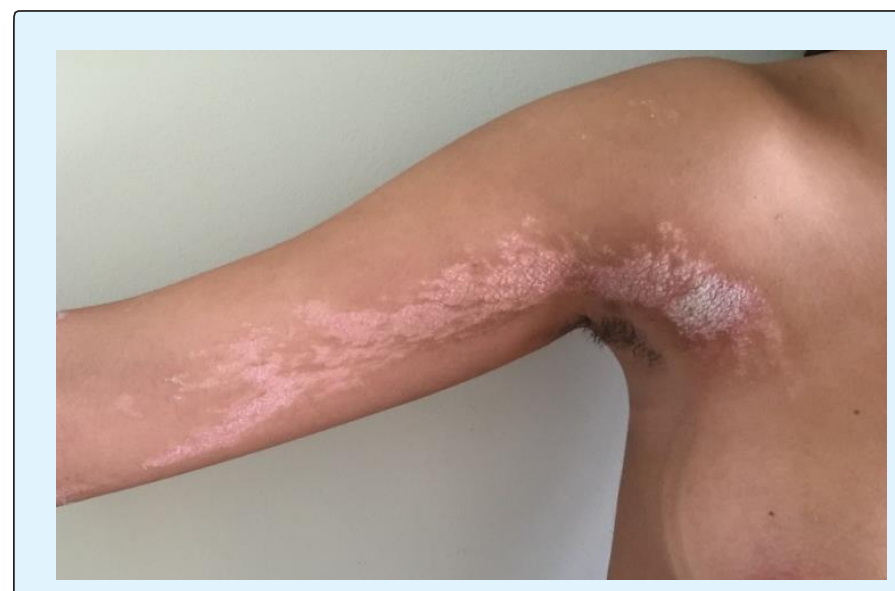

Figure 1: Erythematous-squamous plaques following the lines of Blashkow. 


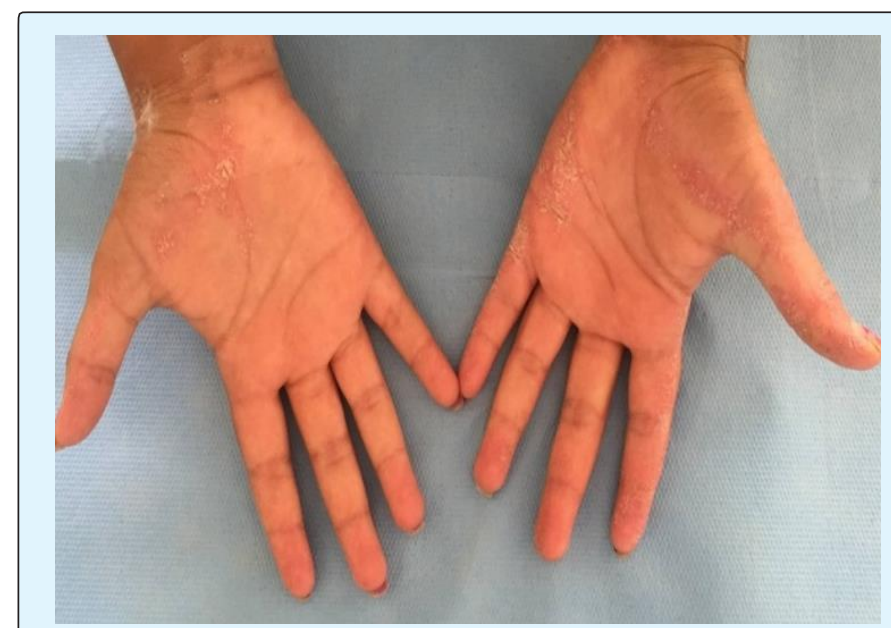

Figure 2: The palmar localisation.

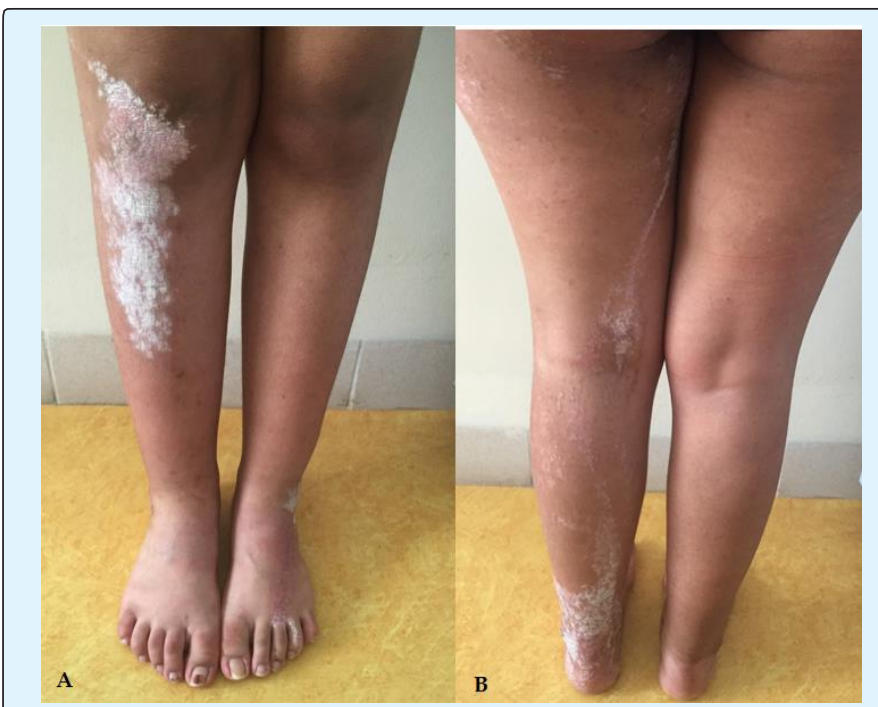

Figure 3: Erythematous and scaly plaques with linear disposition localised to the right leg, a) Anterior face, b) Posterior face.

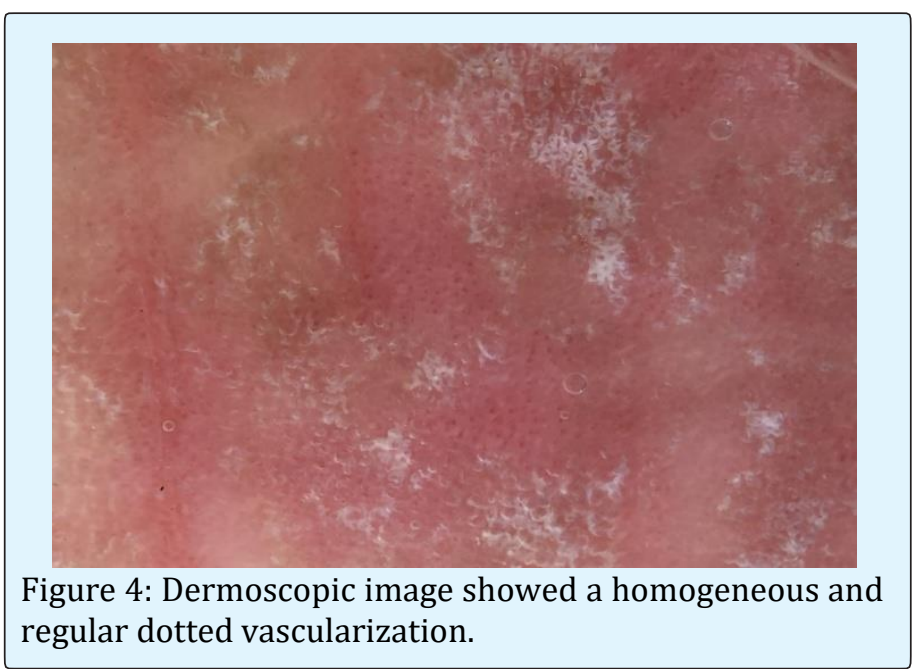

EL Jouari O, et al. Blashkolinear Psoriasis: A Rare Clinical Form. Clin Dermatol J 2018, 3(1): 000138.

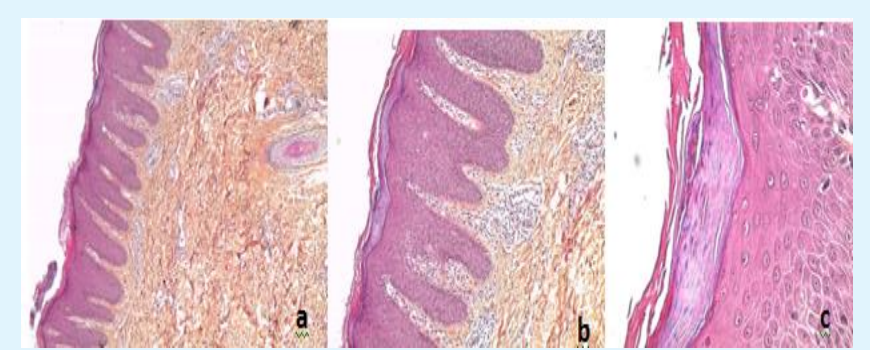

Figure 5: a) Coloration HES G x 50Regular psoriasiform hyperplasia, b) Coloration HES G x 200 Parakeratosis with tortulous vessels of the papillary dermis, c) Coloration HES G x 400Microabcies in parakeratosis.

\section{Discussion}

Linear psoriasis is an unusual subtype of psoriasis first described in 1951. A few cases are reported in the literature. The pathogenesis is still unknown but could be explained by the concept of genetic mosaicism. It can occur in early childhood and defined by presence of linear erythematous and scaly lesions along the lines of Blaschko. Linear psoriasis is often asymptomatic or with mild pruritus. Homogeneous diffuse dotted vascularization is a specific dermoscopic finding of psoriasis. The main differential diagnosis is the inflammatory linear verrucous epidermal nevus which are intensely pruritic and resistant to antipsoriatic treatments. Histologically, linear psoriasis presents Hyperkeratosis parakeratosis associated with agranulosis with elongation of the ridges, thinning of the suprapapillary epidermis and the presence of Munro's microabscess in the stratum corneum, considered as specific of psoriasis. Linear psoriasis characterized by defined a favorable response to antipsoriatic treatment. In contrast our patient doesn't response to topical treatment alone [1-4].

\section{Conclusion}

Linear psoriasis is an entity distinct from psoriasis whose diagnosis requires different anamnestic, physical and histological arguments.

\section{References}

1. Nasimi M, Abedini R, Azizpour A, Nikoo A (2016) Isolated linear blaschkoid psoriasis. Clin Exp Dermatol 41(7): 775-778.

2. Brinca A, Santiago F, Serra D, Andrade P, Vieira R, et al. (2011) Linear psoriasis-a case report. Case Rep Dermatol 3(1): 8-12. 


\section{Clinical Dermatology Open Access Journal}

3. Figueiras Dde A, Cauas RC, Takano DM, Ramos TB, Marinho AK, et al. (2015) Linear psoriasis: case report onthree year old child. An Bras Dermatol 90(3):194-196.
4. Happle R (1991) Somatic recombination may explain linear psoriasis. J Med Genet 28(5): 337. 